\title{
SIGA: Um Ambiente para Criação, Gerenciamento e Execução de WebQuests orientadas ao padrão IMS Learning Design
}

\author{
Juvenal Silva Neto ${ }^{1}$, Angelo Passaro ${ }^{2}$, Gleber Nelson Marques ${ }^{1}$, Clovis Torres \\ Fernandes $^{3}$ \\ ${ }^{1}$ Departamento de Computação - Universidade do Estado de Mato Grosso (MT) \\ 78780-000 - Alto Araguaia - MT - Brazil \\ ${ }^{2}$ Instituto de Estudos Avançados- Divisão de Física Aplicada \\ São José dos Campos, SP- Brazil. \\ ${ }^{3}$ Instituto Tecnológico de Aeronáutica - São José dos Campos, SP - Brazil \\ \{juvenalneto,gleber.nmarques\}@unemat.br, angelo@ieav.cta.br, \\ cloviseita.br
}

Resumo. Este trabalho está sendo conduzido no âmbito de uma pesquisa de mestrado que inclui o desenvolvimento de um sistema gerenciador de aprendizagem, denominado SIGA, baseado na Web e voltado ao ensino/aprendizagem. Este estudo tem dois estágios. No primeiro foi modelada e proposta uma equivalência conceitual entre elementos do modelo WebQuest e o padrão IMS LD em que se baseou o desenvolvimento do Editor WebQuest-LD. No segundo estágio está sendo conduzido um experimento com o uso do ambiente SIGA no contexto da Pós-Graduação em Ciências para que as percepções de alunos e professores a respeito da metodologia WebQuestLD sejam carcterizadas e analisadas.

\section{Cenário de Uso}

É notável que atualmente a Internet, mais especificamente a World Wide Web, está redefinindo radicalmente como nós obtemos informação, e como consequência as formas de ensinar e aprender (Zheng et al. 2008). Como um recurso voltado à aprendizagem, a WWW ou simplesmente Web é utilizada cada vez mais pelos alunos como fonte de informações para construção de conhecimento através de atividades de busca, organização e sistematização de informações. Contudo, muitas vezes os alunos têm dificuldade de escolher as informações úteis e/ou confiáveis, resultando em perda de foco da pesquisa e ineficiência no processo de aprendizagem.

A WebQuest se destaca como uma estratégia educacional moderna baseada na utilização orientada da Web, que visa motivar os alunos para a aprendizagem e que integra a exploração das Tecnologias de Informação e Comunicação (TIC), a aprendizagem baseada na resolução de problemas, no trabalho em projetos colaborativos e ainda, da avaliação formativa (Quaresma 2007; Dodge 1997).

Para facilitar e incrementar a adoção dessa técnica instrucional, foram desenvolvidos editores de WebQuests (Vieira \& Grahl 2008), que possibilitam de forma simplificada a criação de WebQuests já no formato HTML. Contudo, limitar a criação de WebQuests apenas a estes editores e ainda gerar o conteúdo somente no formato 
HTML é limitar as possibilidades de reutilização das WebQuests produzidas por estes editores. Isto pode ser justificado no fato de que WebQuests em HTML são difíceis de serem incorporadas no contexto de LMSs (Learning Management Systems), por não estarem nos formatos aceitos por estas plataformas.

Adicionalmente, no cenário educacional atual, o IMS Global Learning Consortium, é um dos principais fóruns de padronização. Dentre os padrões propostos pelo órgão, o IMS Learning Design (Koper \& Tattersall 2010), aqui referenciado por $\mathrm{LD}$, é um padrão que contém uma metalinguagem para construção de unidades de aprendizado, independente de métodos pedagógicos. $\mathrm{O}$ LD permite várias possibilidades no desenvolvimento de atividades de aprendizagem, tais como a criação de papéis distintos (professor, instrutor, mediador, aluno, etc.) e o acesso a serviços como e-mail e outros existentes em ambientes de apoio à aprendizagem, como fórum e chat.

Neste trabalho apresentamos um ambiente computacional simplificado tipo LMS com acesso por um browser, que inclui o Editor de WebQuests adequado ao padrão LD, tomando como referência o Editor proposto por Camargo \& Fernandes (2010). Nesse ambiente, o professor poderá criar Disciplinas, associar turmas de alunos às disciplinas e inserir material educacional em diversos formatos, incluindo principalmente WebQuests escritas com a ajuda do Editor de WebQuests associado ao ambiente. Cada aluno da turma será capaz de acessar as WebQuests disponíveis numa dada turma, que poderão ser visualizadas por meio de executor que entende o formato do padrão LD e o apresenta num browser qualquer.

\section{Desenvolvimento}

O processo de desenvolvimento do ambiente SIGA iniciou pela análise e modelagem do Editor de WebQuests-LD buscando uma equivalência entre as sessões/etapas da WebQuest aos componentes básicos do padrão LD. Este estudo resultou na proposta de uma WebQuest estruturada pelo LD, conforme esboçado pela Figura 1.

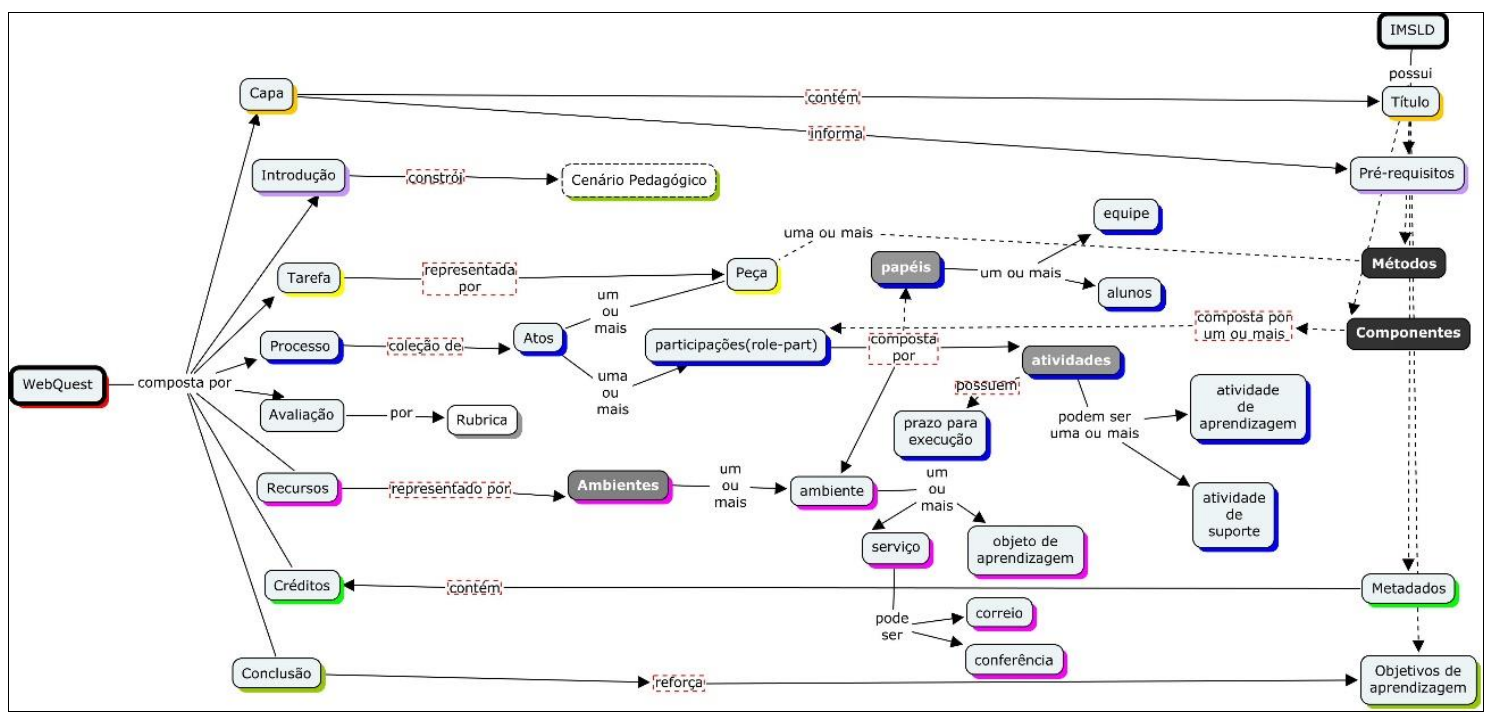

Figura 1: Esquema da equivalência entre WebQuest e LD 
A partir deste modelo híbrido conceitual foi adotado um processo de implementação iterativo e incremental, apoiado em princípios e valores da Engenharia de Software visando atender algumas das melhores práticas da Interação HumanoComputador.

Deste modo, buscou-se definir um ambiente de desenvolvimento fundamentado no padrão MVC (Somerville 2007), com as camadas Modelo (Model), Visualização (View) e Controle (Controller) atuando independentes, o que possibilita o reuso da lógica em novas aplicações e minimiza o impacto das alterações de requisitos de interface sobre a camada de domínio.

O protótipo foi desenvolvido sobre a plataforma Java, utilizando como principal framework o JavaServer Faces, que incorpora o padrão MVC e, por se tratar de um aplicativo Web, adicionalmente a arquitetura cliente-servidor, fez-se uso do JEE, PrimeFaces e Hibernate com MySQL.

Para avaliação da ferramenta, estão sendo realizados alguns experimentos com professores e alunos de graduação e pós-graduação, onde pretende-se levantar os efeitos da experiência de uso tanto do ambiente SIGA quanto da estratégia educacional WebQuest-LD nas atividades de ensino e aprendizagem. Focando principalmente no trabalho do professor, também será realizada uma avaliação de usabilidade da ferramenta, utilizando as 10 (dez) heurísticas de Nielsen (Borges et al. 2012; Nielsen 1994), pois se trata de um método relativamente simples, rápido e bastante efetivo.

\section{Apresentação do software}

Para utilizar o SIGA é necessário que o interessado solicite um convite e na sequência efetue o cadastro a partir da home page (http://www.webquest-ld.com.br) da ferramenta. $\mathrm{O}$ acesso será concedido e o usuário poderá visualizar a Área de Trabalho, contendo o menu principal (Figura1, ítem a) e o painel informativo (Figura 1, ítem b) que apresenta informações importantes sobre a elaboração de conteúdo.



Figura 2: Página inicial do SIGA 
O ambiente oferece dois perfis de acesso, o de professor e aluno. Para o professor estão disponíveis funções de administração, edição de WebQuests e gerenciamento de turmas. Na versão para alunos, o menu oferece a edição dos dados pessoais, contato com desenvolvedor, acesso às turmas e logout. É através do menu Turma que o aluno terá acesso a WebQuest elaborada pelo professor.

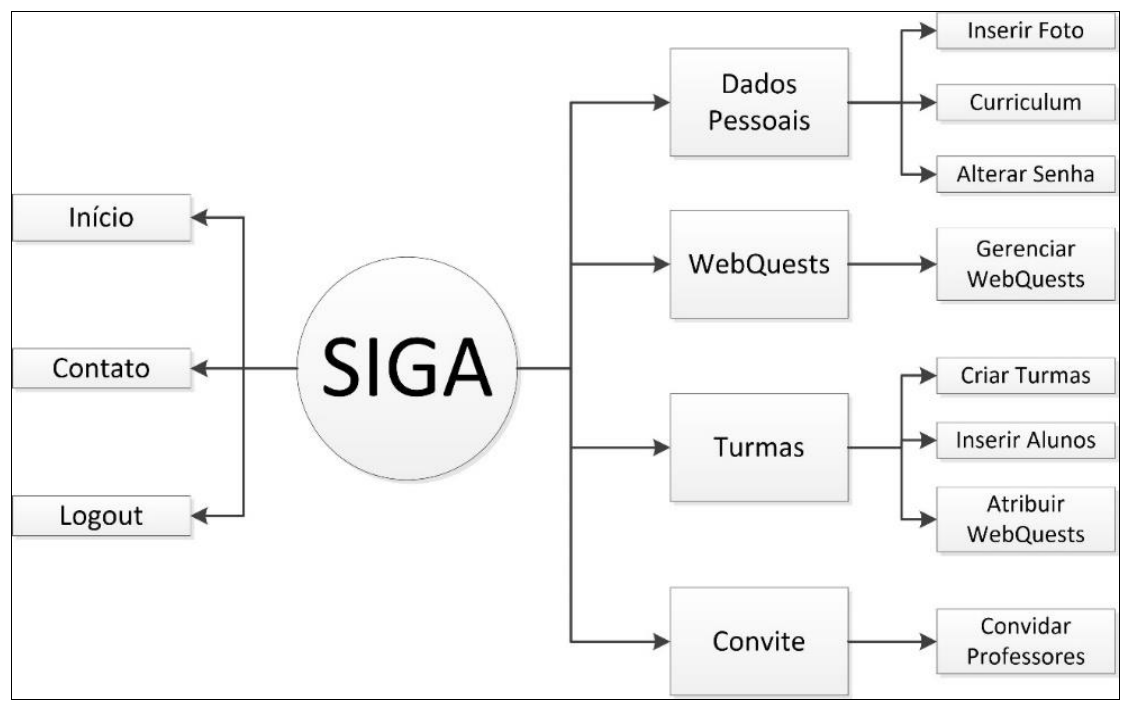

Figura 3: Visão geral do menu principal

No que diz respeito ao Gerenciamento de WebQuests (Figura 4), o ambiente possibilita além da construção e edição de WebQuests, também a importação ( versões desenvolvidas por outros usuários do SIGA, desde que autorizado pelo autor, além da troca do layout (função Modelo) e execução tanto em HTML quanto em IMS LD.

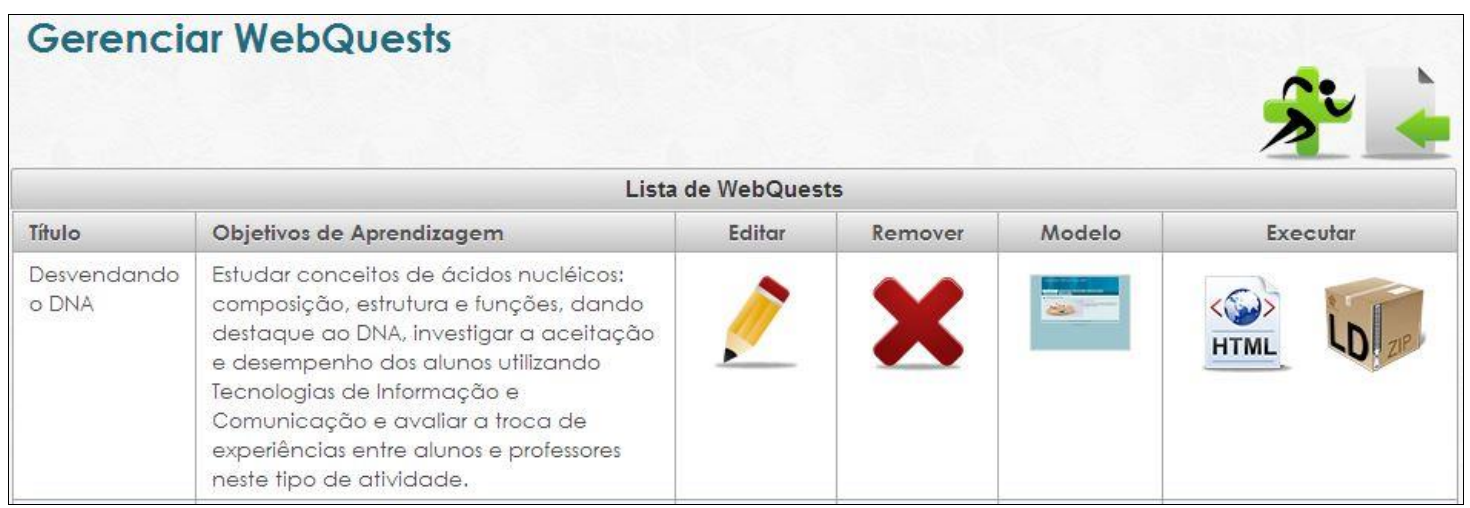

Figura 4: Tela para Gerenciamento de WebQuests

Por meio do botão ( $\left.\hat{\boldsymbol{B}}^{\mathfrak{i}}\right)$ é possível criar uma nova WebQuest. As primeiras informações solicitadas são baseadas nos metadados de uma Unidade de Aprendizagem em LD como, Título, Objetivos de Aprendizagem, Pré-requisitos e Público Alvo.

Para popular a WebQuest deve ser utilizado o ícone Editar. Abaixo do menu principal, serão apresentadas as sessões que compõe uma WebQuest (Capa, Introdução, Tarefa, Processo, Avaliação, Conclusão e Créditos). As setas azuis no final da página devem ser utilizadas para navegar por estas sessões. 
- Capa: utilizando o formulário, são inseridas informações gerais da WebQuest.

- Introdução: um editor de texto simples permite apresentar o tema proposto motivando e desafiando o aprendiz, capturando o interesse pela atividade.

- Tarefa: há um espaço exclusivo para o título que definirá o objeto de estudo (problemática) da WebQuest-LD. O conjunto de atividades necessárias para responder uma TAREFA podem ser organizadas em etapas ou Fases subsequentes, de modo a facilitar as relações que o discente deve aprender.

- Processo: nesta etapa são especificadas quais atividades os alunos deverão realizar para cumprir a Tarefa. Além da descrição, pré-requisitos e objetivos, em cada atividade é necessário atribuir atores e recursos, além de definir o prazo para o término da atividade.

- Avaliação: o ambiente oferece um construtor de Rubricas que será apresentado de forma estática para o aluno. A Rubrica proporciona uma forma mais homogênea e significativa de avaliação, evitando que trabalhos similares sejam analisados sob óticas diferentes.

- Conclusão: o resumo sobre o propósito geral do que foi aprendido e indicações de como o aluno pode continuar os estudos sobre o assunto é informado através de um editor de textos simples, como na Introdução.

- Créditos: através de um formulário é informada a versão da WebQuest-LD construída, a propriedade intelectual, permitindo ou não a cópia para outros usuários do sistema, palavras-chave e colaboração de autoria.

Uma das funcionalidades do ambiente SIGA é possibilitar que uma WebQuest seja executada em dois formatos, HTML (Figura 5), formato mais usual e LD (Figura 6), onde o aluno inicia escolhendo a WebQuest ou ainda, a Unidade de Aprendizado que deseja executar e logo em seguida o papel que irá desempenhar a(s) atividade(s). 


\section{Desvendando o DNA}

\section{Processo}

Na fase 1 você deverá realizar 1 atividade(s), descrita(s) abaixo:

\section{Atividade: 1.1}

Titulo: Conhecer a molécula do DNA

Papéis:

Pesquisador: Por meio dos recursos fornecidos, levantar informações sobre a molécula do DNA.

Pré-requisitos: Ter cursado o primeiro ano do ensino médio.

Objetivos: Adquirir informações essenciais para o entendimento do tema ácidos

nucléicos utilizando diferentes fontes disponiveis na internet. Recursos:

DNA - Estrutura e Replicação

Ácidos Nucleicos - DNA - Compostos Orgânicos

Descrição:

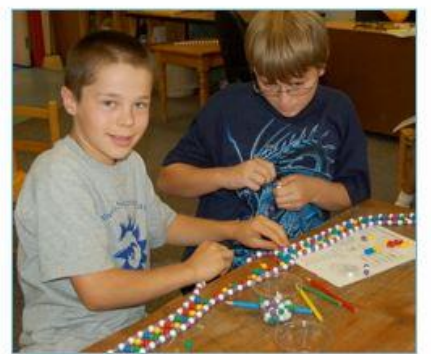

Capa

Introdução

Tarefa

Processo

Avaliação

Conclusão

Créditos

Figura 5: atividade na versão em HMTL

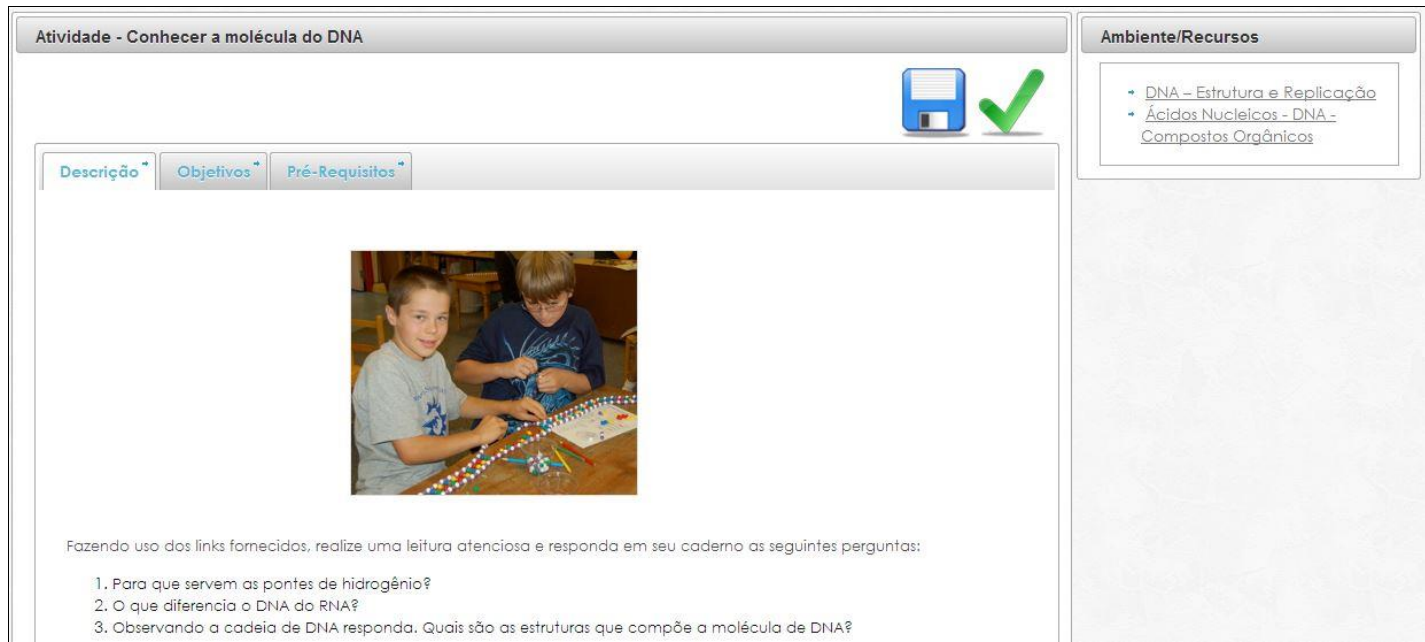

Figura 6: atividades na versão em LD

O ambiente SIGA é um sistema para aprendizagem eletrônica de código aberto e que apesar de utilizar um visual limpo e moderno sugere um novo formato de Edição de WebQuests. Por esta razão, dois vídeos-tutoriais foram produzidos e disponibilizados na Internet para auxiliar nos primeiros passos, conforme indicado na Tabela 1. 


\begin{tabular}{|l|l|}
\hline $\begin{array}{l}\text { Construindo uma WebQuest-LD } \\
\text { no SIGA }\end{array}$ & $\underline{\text { https://www.youtube.com/watch?v=7_UN4_bqves }}$ \\
\hline Como abrir Turmas no SIGA & $\underline{\text { https://www.youtube.com/watch?v=V_JZgzuW Tk }}$ \\
\hline
\end{tabular}

Tabela 1: vídeos-tutoriais

\section{Considerações finais}

O Editor proposto pode contribuir significativamente para o trabalho docente em seus vários níveis, facilitando o desenvolvimento de WebQuests que atendem ao padrão de especificação de aprendizagem IMS Learning Design. Se por um lado a simplicidade e flexibilidade da estrutura da Webquest facilita sua disseminação, por outro, a rígida e detalhada especificação do IMS LD tende a produzir objetos educacionais com maior qualidade, consistência e coerência, e assim, buscamos aliar essas características no sistema SIGA.

Além disso, ao tornar a WQ um IMS LD, possibilitará que a WebQuest se beneficie de inúmeras outras Unidades de Aprendizagem IMS LD, e vice-versa, favorecendo o intercâmbio de objetos de aprendizagem tipo WQ e IMS LD entre os autores de ambas as comunidades. Atualmente, estamos realizando uma pesquisa de campo para experimentação do sistema SIGA em apoio a disciplinas na pós-graduação, em seguida na graduação e na educação básica.

É oportuno destacar que com o desenvolvimento do ambiente SIGA, um trabalho futuro consiste em promover a integração dele com um Editor de Rubricas (Carvalho \& Fernandes 2012), visando desenvolver uma família de editores de módulos de aprendizagem que poderão futuramente ser incorporados como ferramentas em ambientes de apoio à aprendizagem baseados na Web, como o TIDIA-Ae/Sakai e Moodle.

\section{Referências}

Borges, K., Rapkiewicz, C. \& Feijó, A., 2012. Usando heurísticas de Nielsen para avaliar objetos de aprendizagem e softwares educacionais: um estudo exploratório na área de Matemática para ensino superior. Anais do Workshop de Informática .... Available at: http://br-ie.org/pub/index.php/wie/article/view/2130 [Accessed October 30, 2013].

Camargo, E. \& Fernandes, C., 2010. WQE: um Editor de WebQuests Versátil. Simpósio Brasileiro de Informática na Educação, p.10. Available at: http://ceiesbc.educacao.ws/pub/index.php/sbie/article/view/1485 [Accessed November 12, 2012].

Carvalho, R.S. \& Fernandes, C.T., 2012. Easy Rubric: um Editor de Rubricas no Padrão IMS Rubric. Anais do Workshop do Congresso Brasileiro de Informática na Educação, pp.10-11. Available at: http://www.brie.org/pub/index.php/wcbie/article/view/1949 [Accessed April 20, 2013]. 
Dodge, B., 1997. Some Thoughts About WebQuests. San Diego State University. Available at: http://webquest.sdsu.edu/about_webquests.html [Accessed February $13,2013]$.

Koper, R. \& Tattersall, C., 2010. Learning Design R. Koper \& C. Tattersall, eds., Springer Netherlands. Available at: springeronline.com.

Nielsen, J., 1994. Usability inspection methods. Conference companion on Human factors in computing ..., pp.413-414. Available at: http://dl.acm.org/citation.cfm?id=260531 [Accessed October 30, 2013].

Quaresma, P., 2007. Concepção e exploração de uma WebQuest para a introdução ao ensino da fisica. Universidade de Avieiro. Available at: http://ria.ua.pt/handle/10773/3387 [Accessed February 12, 2013].

Somerville, I., 2007. Engenharia de Software $8^{\text {a }}$ ed., São Paulo: Pearson Education do Brasil.

Vieira, Y. \& Grahl, E., 2008. Ferramenta web para criação e gerenciamento de WebQuests com Avaliações On-line. Anais do VII Simpósio de Informática da Região Centro do RS, p.9. Available at: http://www.sirc.unifra.br/artigos2008/42880_1.pdf [Accessed June 10, 2013].

Zheng, R. et al., 2008. WebQuests as perceived by teachers: implications for online teaching and learning. Journal of Computer Assisted Learning, 24(4), pp.295-304. Available at: http://doi.wiley.com/10.1111/j.1365-2729.2007.00261.x [Accessed June 10, 2013]. 